\title{
Accommodating Nomadism and
}

Mobility: Challenging the sedentarist

binary approach to provision for

\section{Gypsies, Travellers and Roma.}

James, Zoe

http://hdl.handle.net/10026.1/13263

10.1108/IJSSP-10-2018-0177

International Journal of Sociology and Social Policy

Emerald

All content in PEARL is protected by copyright law. Author manuscripts are made available in accordance with publisher policies. Please cite only the published version using the details provided on the item record or document. In the absence of an open licence (e.g. Creative Commons), permissions for further reuse of content should be sought from the publisher or author. 


\section{Accommodating Nomadism and Mobility: Challenging the} sedentarist binary approach to provision for Gypsies, Travellers and Roma.

\begin{tabular}{|r|l|}
\hline Journal: & International Journal of Sociology and Social Policy \\
\hline Manuscript ID & IJSSP-10-2018-0177.R2 \\
\hline Manuscript Type: & Original Article \\
\hline Keywords: & Anti-Gypsyism, Exclusion, Planning, Provision, Europe \\
\hline \multicolumn{2}{|l}{} \\
\end{tabular}




\section{Accommodating Nomadism and Mobility: Challenging the sedentarist binary approach to provision for Gypsies, Travellers and Roma.}

\section{Introduction}

This paper presents an argument for a more nuanced approach to provision for Gypsies, Travellers and Roma in Europe that embraces their cultural nomadism. Using empirical data gathered in the UK, the paper evidences the harms experienced by Gypsies and Travellers as consequence of a lack of provision. We relate these harms to the underpinning sedentarist binary logic of policy in England and Wales and suggest that a similar logic informs policy and practice throughout the European environment. Therefore, the paper recommends consideration of Gypsies, Travellers and Roma nomadism within all aspects of policy beyond a simplistic sedentarist binary approach in the future.

Gypsies, Travellers and Roma constitute the largest minority 'community' in Europe and are often considered the most vilified (James, 2014). They are a diverse range of people, whose ethnicity bears similarities in parts, but whose common identity is borne of their cultural nomadism (Kabachnik, 2009). The culturally nomadic identity of Gypsies, Travellers and Roma refers to their predisposition to think and act in a boundless fashion. Simplistic analyses of nomadism equate it to mobility, whereas studies of Gypsies, Travellers and Roma have long-recognised the nuanced and variable nature of cultural nomadism that includes a range of approaches to living that are bound up with notions of freedom and autonomy (Halfacree, 1996; Levinson and Sparkes, 2004; Acton, 2010; Shubin, 2010). Cultural nomadism is lived contemporarily by some Gypsies, Travellers and Roma as mobility in parts of Europe and in other areas it is lived from a settled base, either in housing or on a fixed site in a temporary structure. The settlement of Gypsies, Travellers and Roma is often associated with assimilationist state policies that have aimed to resolve the 'problem' of Gypsy, Traveller and Roma mobility through a process of deculturation (lovita and Schurr, 2004). However, Gypsies, Travellers and Roma have survived assimilation policies, often by embracing their essential cultural or ethnic identities as a response to their exclusion from mainstream culture and provision (Acton, 2010). Despite the existence of Europe-wide policies of integration and inclusion such as the 2011 EU Framework for National Roma Integration Strategies which have been developed following successful lobbying by civil society organisations led by, or representing Gypsy, Traveller and Roma communities, Government practices continue to supress and oppress them (Brown, et al, 2015).

As is evident from this brief introduction, there has been political will to challenge the exclusion of Gypsy, Traveller and Roma communities at the macro-level of European government and at the micro-level of grass roots change-makers from civil society organisations. This has not been translated successfully however within the nation states that make up the European Union (James and Smith, 2017). Hate crime statistics and reports identify Gypsies, Travellers and Roma as experiencing high levels of victimisation on the basis of their identity (European Union Minorities and Discrimination Survey, 2012, OSCE, 2012, 2011) alongside extremely poor outcomes in relation to health, education and welfare (Brearley, 2001; Wilkin et al, 2010; Frazer and Marlier, 2011; Greenfields and Brindley, 2016). Hate speech towards Gypsies, Travellers and Roma is commonly used by mainstream politicians and civil servants, and public attitudes towards Gypsies, Travellers and Roma are extremely negative (Mirga, 2009). There is some distinction between varying nation states' treatment of Gypsies, Travellers and Roma, but the problematisation of these communities 
cannot be attributed to particular parts of Europe or types of government regime. Although each Gypsy, Traveller and Roma community has a distinct history, culture and experience of discrimination and victimisation, their overarching vilification appears to be best understood by examining that minority's experience (Phillips and Bowling, 2008) in light of the tensions that exist between sedentarism and nomadism, or perceptions of Gypsies, Travellers and Roma in relation to mobility (Kabachnik, 2009), alongside recognition of their experiences of racism (Ellis and McWhirter, 2008).

The failure to appropriately accommodate Gypsies, Travellers and Roma who are settled or mobile has been repeatedly identified as the key driver of their exclusion. Sedentary society has not given Gypsies, Travellers and Roma places to stop and stay, or if they have, they have been exclusionary as they have failed to embrace the mobility of some Gypsies, Travellers and Roma (Stewart, 2012). This is because sedentarist notions of what nomadism is have been imposed on those communities from a binary perspective: nomadic people are considered those that have been expected to be constantly mobile without stopping and non-nomadic people are those who have been expected to stop and never be mobile. This has not allowed for the cultural nomadism of Gypsies, Travellers and Roma in the late modern era to be recognised. The sedentarist binary approach to nomadic identity detailed here has been embedded in planning policy in England and Wales that has defined 'travellers' for accommodation purposes as only those people who spend some of their time being mobile (DCLG, 2015). This policy change has extensive implications as it precludes those people who are culturally nomadic, rather than mobile, from planning provision, including communities recognised by race relations legislation as ethnic groups.

This paper sets out empirical data on the accommodation and mobility of Gypsies and Travellers in a rural county of England, gathered as part of a Gypsy and Traveller Accommodation Assessment (GTAA) (Southern, James and Buckman, 2015). Roma are not included in such Accommodation Assessments due to their inclusion in assessment of fixed housing, alongside the settled population. The paper provides evidence of the continuing lack of accommodation for Gypsies and Travellers in England (Cemlyn et al, 2009) and the social harms associated with it. Further, the paper is subsequently able to consider the implications of planning policy in England and Wales which is based on a misunderstanding of the meaning of 'cultural nomadism' for Gypsies, Travellers and Roma. The paper is therefore able to inform our knowledge and understanding of the wider policy arena in Europe. It suggests that nation states do not respond to the pressure placed on them by macro and micro level organisations for inclusion of Gypsies, Travellers and Roma because they fail to recognise what cultural nomadism means, resorting instead to a simple sedentarist binary definition that cannot serve the needs of those communities.

\section{The policy environment}

In the UK it has been estimated that Gypsies and Travellers constitute $0.6 \%$ of the population (ODPM, 2006), though this estimate has been contested for its reliance on annual 'caravan counts' that have been criticised for their lack of inclusion of all Gypsies and Travellers, poor accuracy and weak reliability (Niner, 2004). The ability to quantify numbers of Gypsies and Travellers is therefore difficult, but a general estimate of the literature in this area might suggest that approximately 1$1.5 \%$ of the UK population are Gypsies and Travellers (Greenfields and Smith, 2009). 
Some Gypsies and Travellers in England have legislatively protected ethnicities: Romany English Gypsies, Scottish, Welsh and Irish Travellers. Showpeople, alternatively, are recognised within policy as having specific needs to accommodate their provision of fairgrounds but they are not recognised as an ethnic group and neither are New Travellers (for a full discussion of Gypsy and Traveller identity see Clark, 2006). However, depending on the circumstances of Gypsies and Travellers and the policy environment, their identity is defined at a local level. This means that Gypsies and Travellers who do not live in 'bricks and mortar' accommodation are subject to the definition utilised in the planning system. The planning system, using associated planning law and policy, acts as a 'critical interface' between Gypsies and Travellers and the state as it provides accommodation space to those communities and thus facilitates, 'secure family life and access to vital welfare services'(Ellis and McWhiter, 2008:82). A crisis of accommodation for Gypsies and Travellers in the UK has long been recognised (Morris and Clements, 2002, Cemlyn et al, 2009) and the New Labour government (1997-2010) was successfully lobbied by civil society organisations to recognise the accommodation needs of Gypsies and Travellers, which led to their specific inclusion in the Housing Act 2004 and subsequent completion of GTAAs by local authorities. Those GTAAs have rarely resulted in actual provision however (Brown et al, 2010) and the lack of either settled or transitory accommodation for Gypsies and Travellers remains a problem throughout the UK. Consequently Gypsies and Travellers live in spaces that are often considered illegitimate as they do not conform to either planning requirements or are not deemed appropriate use of that space as described below in the research methodology of this paper.

The Conservative led Coalition government (2010-2015), under their 'localism' agenda (which served to devolve responsibility for local issues to geographically defined localities), carried out a review of policies on the provision and use of land for Gypsies and Travellers. Their 'local' approach to delivery of services for communities was enshrined in the Localism Act 2011 which devolved responsibilities from regional bodies to local authorities, dissolving Regional Spatial Strategies that had set out Gypsy and Traveller accommodation targets for local authorities under the previous government. Of potentially greater significance for Gypsies and Travellers however, has been the incorporation in the Localism Act of a requirement for local authorities to work directly with local communities to develop local plans, thereby taking account of settled communities' views, as well as Gypsies and Travellers' in determining their accommodation needs. Given the negative public perception of Gypsies and Travellers, which will be addressed further below, it is unsurprising that the inclusion of their views on accommodation provision has resulted in lobbying against the provision of legitimate spaces for Gypsies and Travellers, which has been tacitly supported by local authorities whose planning officers may recommend accommodation, but whose councillors are fearful of losing votes (Erfani-Ghettani, 2012).

Following the retrenchment of policies to accommodate Gypsies and Travellers by the Coalition government, within three months of taking office the Conservative administration ( 2015 - present) had introduced new legislation to remove the requirement of local authorities to specifically measure the accommodation needs of Gypsies and Travellers and had re-drafted planning policy that processes provision of accommodation for Gypsies and Travellers. The new 'Planning Policy for Traveller Sites' (2015) specifically changed the definition of Gypsies and Travellers so as to negate their status as 'travellers' for planning purposes if they stop travelling on a permanent basis, as noted above. Thus, the mobility of Gypsies and Travellers, rather than their culture, was determined as the defining characteristic of their nomadism by this new policy. 
The new planning policy has extensive implications for Gypsies and Travellers, affirming the concerns raised by Ellis and McWhirter (2008:80) that 'the fate of Traveller-Gypsies stands as an explicit reminder of how the system of land-use regulation can act as a coercive and repressive instrument'. Concerns have been raised that those Gypsies and Travellers who have had to stop 'travelling' due to infirmity or old age may be at risk of eviction from their homes on sites or will be unable to attain planning permission for a settled site to live on (1) (Acton, 2015; Friends, Families and Travellers, 2015; The Traveller Movement, 2015; Johnson and Ryder, 2015). The policy has assumed that an individual's identity as a Gypsy or Traveller is based purely on being mobile, rather than being from a particular ethnicity and/or being culturally nomadic, thus it has failed to recognise the nomadic diversity of Gypsy and Traveller communities and/or associated race relations legislation. The policy therefore raises serious welfare concerns for Gypsies and Travellers and ironically could result in Gypsies and Travellers being compelled to travel more when there are insufficient legitimate spaces available for them to do so, as detailed above. Indeed, the new policy acts to exacerbate what Kabachnik (2010) has previously noted; one of the failures of policy that has fallen out of the sedentarist binary notion of nomadism is the lack of recognition of the need for places to facilitate mobility (see also, Shubin, 2011, and Merriman, 2015 on how mobilities impact all aspect of contemporary culture). In order to live a mobile nomadic lifestyle, an individual must move from place to place and thus be accommodated on that journey with legitimate transitory places to stop on. Those Gypsies and Travellers that are nomadic and not mobile also need to live according to their cultural requirements on sites, i.e. not in bricks and mortar accommodation.

The impact of these policy changes are brought into sharp focus when examined within the context of empirical data about Gypsies and Travellers lives gathered through a recent GTAA in Cornwall, England.

\section{Methodological note}

The Cornwall GTAA survey was completed between August and November 2015 and included interviews with 187 Gypsies and Travellers who lived in different types of accommodation across the county. This included Gypsies and Travellers who normally resided on approved sites as well as those who lived in illegal spaces and it is important to distinguish between the two. Local Authority (or socially rented) sites and authorised privately owned sites are those sites that are officially deemed legal through having some sort of planning permission. The permission may have been granted on a permanent or temporary basis and it could also include the provisions of a Certificate of Lawful Use (CLU). These legally recognised sites can be used as residential/permanent living spaces; they can be used as transit sites where Gypsies and Travellers reside temporarily (usually for periods of up to three months); or they can be used as temporary stopping places which are safe shorter stay sites (usually up to 10 days) for Gypsies and Travellers to stop-over as they are travelling. Unauthorised sites, on the other hand, describe settled sites on any land which does not have planning permission and these sites may or may not be tolerated by the Local Authority. Unauthorised encampments are places that have been occupied, generally on the roadside, for only a short period of time while Gypsies and Travellers are in transit. They are distinct here due to their temporary nature and the illegitimate use of space that they often comprise (such as playing fields, car parks and lay-bys).

At the time of the study there were three socially rented sites in Cornwall, all of which were designed for residential (as opposed to transit or temporary) use; plus 63 privately owned sites that 
had been granted some sort of planning permission, many of which were small family owned sites that had been developed on their own land. A bespoke survey was designed for use with Gypsies and Travellers who lived in all different types of accommodation including those who lived in bricks and mortar accommodation rather than on a site. This was piloted and subsequently rolled out by a respected local Gypsy and Traveller support organisation and each completed survey was then passed back to the research team for data entry and analysis.

Because there is no existing sampling frame for this population, a snowball sampling approach was utilised which effectively targeted groups in known (Council and private) sites in the first instance and used their contacts to access other, harder to reach, Gypsies and Travellers. Although snowball sampling is sometimes considered unrepresentative, it is a perfectly valid strategy that is sensitive to the shifting population and enabled access to be gained, not just to people living on authorised sites, but also to people living in unauthorised spaces; and in bricks and mortar accommodation which tend to be the hardest groups to access (Sturgis, 2008). Additionally, the survey team approached Gypsies and Travellers opportunistically at events and festivals and by the roadside when they became aware of people coming into Cornwall.

\section{Our survey sample}

Table 1 presents the survey profile which has been re-classified from the original GTAA for the purposes of this paper so that all those people who had self-classified in the GTAA as 'other', referring to themselves as, for example, 'free man' or 'human being', but were living as New Travellers are included as such. Please note that due to the small numbers involved we have included the one Irish Traveller and one Welsh Traveller who completed the survey within the 'other' category.

Table 1: Profile of our re-classified Sample

\begin{tabular}{|l|c|c|}
\hline Re-classified Group & Number & Percentage \\
\hline English Gypsy/Romany & 85 & $45 \%$ \\
\hline New Traveller & 89 & $48 \%$ \\
\hline Showpeople & 3 & $2 \%$ \\
\hline 'Other' & 10 & $5 \%$ \\
\hline TOTALS & $\mathbf{1 8 7}$ & $\mathbf{1 0 0 \%}$ \\
\hline
\end{tabular}

Source: Southern, James and Buckman, 2015. Base: 187 respondents.

Of the 187 Gypsies and Travellers that engaged with the survey, 105 were female, 78 were male and the remaining four did not specify. Delving further into the data, almost three-quarters of the English Gypsy/Romany respondents were female but the New Traveller and 'other' categories were much more balanced. This may reflect the increased engagement of women from Romany Gypsy communities in their own governance (Walker Hudson, 2009). There were only three Showpeople within our sample, hence the findings should be treated with caution, but they were all male and the survey fieldworkers were informed that the women would not speak to them without their husbands being present, perhaps representing the difference between traditional Gypsy and Traveller communities (Okely, 1983).

The sample represented a good spread of age bands with the highest proportion being in the 41-50 age-bracket. The profile of our respondents was broadly representative of the Gypsy and Traveller 
population nationally, which has a higher proportion of younger people compared to the settled population which is ageing (Cemlyn et al, 2009). However, there were some interesting differences between the groups. The data showed a higher proportion of English Gypsy/Romany respondents who were under 30 years of age but they were also the only category with respondents who were over 70. Comparing different groups we can see that $20 \%$ of English Gypsy/Romany respondents were in the over 60 bracket but just $2 \%$ of New Travellers were. This research finding is interesting as it implies that New Travellers are less likely to live on sites when they are younger or older. Hence, the time of life when individuals are most vulnerable, when very young and very old, are less likely to be lived 'on-site' by New Travellers. This could be explained as being due to the cultural nomadism that Gypsy and Traveller ethnicity brings to the lived experience. With the rules of mochadi determining Romany Gypsy lifestyles, it would never be appropriate to live in bricks and mortar accommodation during the life course (Okely, 1983). New Travellers therefore may assimilate in to sedentary society during specific periods of their lives, whereas traditional Gypsies and Travellers are more reliant on living on sites. This finding emphasises the vulnerability of traditional Gypsies and Travellers who live in a settled fashion on sites, but may be required to become mobile or assimilate in to bricks and mortar accommodation as a consequence of the new 'Planning Policy for Traveller Sites' (2015), neither of which would meet their cultural needs and could place them at risk. As previously noted by Thomas (2000) and Ni Shuinear (1994) the racism against Gypsies and Travellers that occurs via public policy should not be conflated with antinomadic sentiment, but rather considered in conjunction with it. In this instance, the new planning policy is likely to create fault lines in provision that result in ethnicity determining provision.

\section{Accommodation circumstances}

The survey required respondents to indicate from a list of options the type of 'site' or accommodation they usually occupied. The results are presented in Table 2 and illustrate that $97 \%$ of the English Gypsies/Romany respondents and $100 \%$ of the Travelling Showpeople lived in places that were officially deemed legal whereas only $48 \%$ of New Travellers did so. Over half (57\%) of the English Gypsies/Romany within our sample specifically lived on a socially rented site which contrasts significantly with the profile of the other respondents, none of whom lived on a socially rented site. It is unsurprising that Romany Gypsies have attained approved site provision given the legitimacy provided to Romany Gypsies historically that has resulted in their perception as an authentic Gypsy and Traveller community, conforming to the 'Gypsy myth' (Holloway, 2005, James, 2014). However, as will be seen below, the provision of limited spaces to some Gypsies and Travellers has meant that those spaces are not necessarily appropriate or well managed. Further, as identified above, the legitimacy of Gypsies and Travellers has been questioned by the 'Planning Policy for Travellers' (2015) given that ethnic groups of Gypsies and Travellers who are less likely to be mobile may potentially lose their right to live on sites that do not have security of tenure.

Data showed that the New Travellers within our sample were far more likely to be residing either at the roadside or in another unauthorised space (either tolerated by the Local Authority or otherwise) than any other group. One of our New Traveller respondents had been living in a car-park for over five years, tolerated by the Council because there was nowhere suitable to move them to but living in constant fear of eviction. New Travellers were also more likely to be living on private sites (either self-owned or rented from another landlord) that did not have planning permission. Interestingly, our sample contained nine respondents who lived on an authorised non-Gypsy site (such as a 
caravan park) which are not illegal but may be seen as unsuitable in many respects. Eight of these were also New Travellers. It is possible to see here that, given the status of their accommodation as largely illegal and therefore temporary, it is likely that New Travellers would align to the new planning policy requirements for mobility, and thus be more able to apply for legal accommodation in future. This is paradoxical, given that New Travellers are less likely to rely on site provision over their entire life course as noted above. It should also be noted in Table 2 below that the GTAA found no transitory site provision for Gypsies and Travellers that would facilitate their legal mobility.

Table 2: Type of site usually occupied by respondents

\begin{tabular}{|c|c|c|c|c|c|}
\hline & & $\begin{array}{l}\text { English } \\
\text { Gypsy/ } \\
\text { Romany }\end{array}$ & $\begin{array}{c}\text { New } \\
\text { Traveller }\end{array}$ & Showpeople & Other \\
\hline \multirow{6}{*}{$\begin{array}{l}\text { LEGALLY OCCUPIED } \\
\text { SITES \& } \\
\text { ACCOMMODATION }\end{array}$} & $\begin{array}{l}\text { Socially rented (Local } \\
\text { Authority site) }\end{array}$ & $48(57 \%)$ & 0 & 0 & 0 \\
\hline & $\begin{array}{l}\text { Self-owned site with } \\
\text { planning permission }\end{array}$ & $15(18 \%)$ & $10(11 \%)$ & $2(67 \%)$ & $2(20 \%)$ \\
\hline & $\begin{array}{l}\text { Privately rented site with } \\
\text { planning permission }\end{array}$ & $6(7 \%)$ & $19(22 \%)$ & $1(33 \%)$ & $2(20 \%)$ \\
\hline & $\begin{array}{l}\text { Authorised non-Gypsy site } \\
\text { (e.g. caravan park) }\end{array}$ & $1(1 \%)$ & $8(9 \%)$ & 0 & 0 \\
\hline & Bricks and mortar - owned & $5(6 \%)$ & 0 & 0 & 0 \\
\hline & Bricks and mortar - rented & $7(8 \%)$ & $5(6 \%)$ & 0 & $3(30 \%)$ \\
\hline TOTAL & & 82 (97\%) & $42(48 \%)$ & $3(100 \%)$ & $7(70 \%)$ \\
\hline \multirow[t]{6}{*}{$\begin{array}{l}\text { ILLEGALLY } \\
\text { OCCUPIED SPACES }\end{array}$} & $\begin{array}{l}\text { Self-owned site without } \\
\text { planning permission }\end{array}$ & 0 & $4(5 \%)$ & 0 & $1(10 \%)$ \\
\hline & $\begin{array}{l}\text { Privately rented site } \\
\text { without planning } \\
\text { permission }\end{array}$ & $2(2 \%)$ & $8(9 \%)$ & 0 & 0 \\
\hline & $\begin{array}{l}\text { Unauthorised - at the } \\
\text { roadside }\end{array}$ & $1(1 \%)$ & $15(17 \%)$ & 0 & $1(10 \%)$ \\
\hline & $\begin{array}{l}\text { Unauthorised - officially } \\
\text { tolerated }\end{array}$ & 0 & $7(8 \%)$ & 0 & 0 \\
\hline & $\begin{array}{l}\text { Unauthorised-unofficially } \\
\text { tolerated }\end{array}$ & 0 & $5(6 \%)$ & 0 & $1(10 \%)$ \\
\hline & Unauthorised - 'other' & 0 & $6(7 \%)$ & 0 & 0 \\
\hline TOTAL & & $3(3 \%)$ & $45(52 \%)$ & 0 & $3(30 \%)$ \\
\hline
\end{tabular}

Source: Southern, James and Buckman, 2015. Base: 185 respondents who answered the question.

Respondents were asked to rate the condition of their 'site' on a scale of one to five with one being very poor and five being very good. Given that research has previously shown that Gypsies and Travellers have very poor outcomes in relation to their health and welfare as a consequence of a lack of and/or poor accommodation, it was necessary to consider whether site conditions have improved (Cemlyn et al, 2009, Brown et al, 2010). The results, presented in Figure 1, showed that despite the fact that a higher percentage of English Gypsies/Romany from our sample lived on legal sites, they were much more likely to describe the condition of their site as poor or very poor. Hence, it is important to note that the authenticity of Romany Gypsies, and their subsequent historical recognition in the provision of sites, has not resulted in their social inclusion. Rather, they have been placed in living conditions that are very poor and likely to impact negatively on their health and welfare which may be exacerbated by their vulnerability, as their communities include the very young and very old. The lack of provision of good quality sites is despite the availability of 
government grants for local authority site refurbishment, the take up of which is variable and evidence for which is lacking (Brown et al, 2010).

Figure 1: Rating of site condition

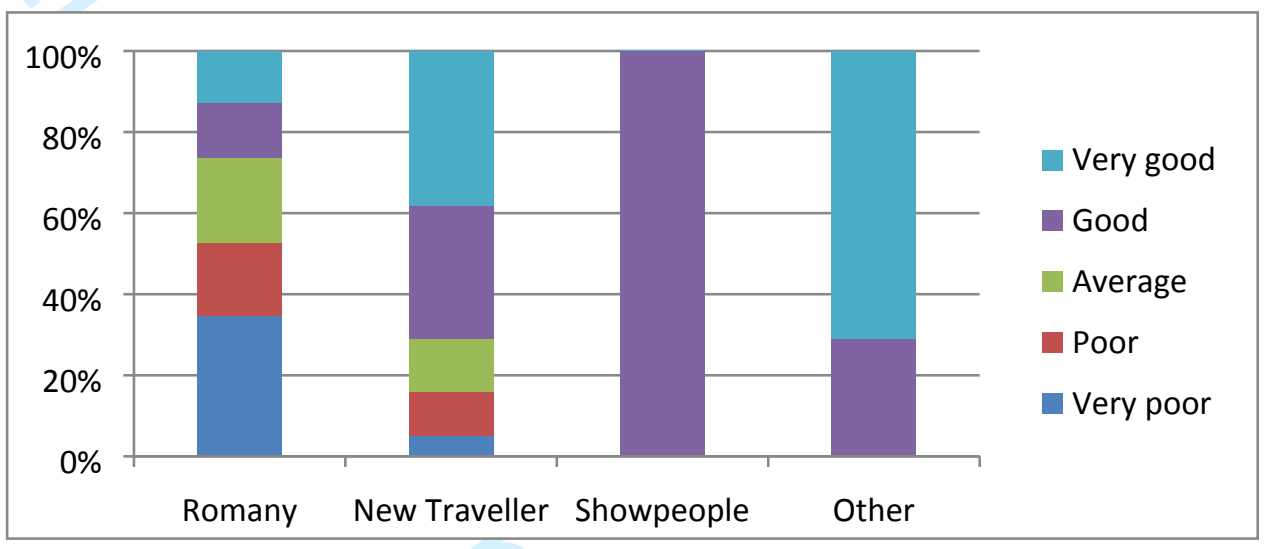

Source: Southern, James and Buckman, 2015. Base 145 respondents who answered the question.

Our English Gypsies/Romany respondents were also more likely to have experienced a range of issues on their site, with particularly large numbers of people having reported issues with pests and vermin as well as fly-tipping as can be seen in Table 3. Of note, those respondents who lived on socially rented sites faced particular issues with pests/vermin (mentioned by $98 \%$ of them); and flytipping (mentioned by 70\%). It is apparent then, that accusations of 'dirtyness' commonly made against Gypsies and Travellers within media and wider social discourse to stigmatise communities and identify their 'otherness' (Sibley, 1988) may paradoxically be due to the anti-social actions of sedentary communities.

The most frequently reported issue for the New Travellers within our sample was with neighbours and local people. Interestingly, for the New Travellers who experienced issues with neighbours or local people there was very little difference between the responses of those who lived on legal or illegal sites. The community tension reported by New Travellers may be a consequence of the higher likelihood of them living in illegitimate places that are illegal. It may also be explained by their lack of alignment to some of the expectations of sedentary communities' myth of the Romany Gypsy identity (Holloway, 2005), despite New Travellers often living in traditional Gypsy and Travellers caravans, vardos and benders. Importantly, it is worth noting here that the increased capacity of New Travellers to access legal accommodation following the introduction of the new planning policy highlighted above, and discussed further below, may in reality be stymied by local objections. As noted earlier in this paper, the Localism Act 2011 allows public opinion to determine local plans. Given the dislike of New Travellers by sedentarists evidenced here, it seems less likely that provision for New Travellers would be made.

Also of interest is the fact that $25 \%$ of our English Gypsy/Romany respondents had experienced negative contact with police, given that the vast majority of them were residing on legal sites. When broken down in more detail, the data shows that this particularly affected those English Gypsy/Romany respondents who lived on private sites, although $19 \%$ of those people who lived on Council sites also reported issues with police activities. For New Travellers, police activities only affected those respondents who lived on illegal sites. New Travellers tend to live in more 'hidden 
spaces' than traditional Gypsies and Travellers, which may explain their elusion from police activities (James, 2007). The finding that traditional Gypsies and Travellers have been subject to police activities is important, as it aligns with other research in this area but elucidates that research as previous studies have tended to focus on the policing of illegal accommodation (James, 2014). Targeted policing of Gypsies and Travellers is highly problematic due to its capacity to reduce confidence in policing amongst those communities, further socially exclude them and therefore augment tensions with sedentarists (James, 2014).

Table 3: Issues experienced on site

\begin{tabular}{|l|c|c|c|c|}
\hline & $\begin{array}{c}\text { English } \\
\text { Gypsy/Romany }\end{array}$ & New Traveller & Showpeople & Other \\
\hline Pests/vermin & $52(95 \%)$ & $15(30 \%)$ & 0 & $1(20 \%)$ \\
\hline Security & $18(33 \%)$ & $13(26 \%)$ & 0 & $1(20 \%)$ \\
\hline $\begin{array}{l}\text { Neighbours/ } \\
\text { local people }\end{array}$ & $24(44 \%)$ & $34(68 \%)$ & 0 & $3(60 \%)$ \\
\hline Fly-tipping & $33(60 \%)$ & $16(32 \%)$ & $1(33 \%)$ & $2(40 \%)$ \\
\hline Police activities & $14(25 \%)$ & $4(8 \%)$ & 0 & $1(20 \%)$ \\
\hline
\end{tabular}

Source: Southern, James and Buckman, 2015. Base 113 respondents who answered the question. Note: this was a multiresponse question hence percentages do not total 100.

Table 4: Preferred accommodation

\begin{tabular}{|c|c|c|c|c|}
\hline & $\begin{array}{c}\text { English } \\
\text { Gypsy/Romany }\end{array}$ & New Traveller & Showpeople & Other \\
\hline \multicolumn{5}{|c|}{ IDEALLY } \\
\hline Socially Rented Site & $32(39 \%)$ & $2(2 \%)$ & 0 & $2(22 \%)$ \\
\hline Self-owned site & $48(58 \%)$ & $67(83 \%)$ & $3(100 \%)$ & $8(89 \%)$ \\
\hline $\begin{array}{l}\text { Site owned by another } \\
\text { landlord }\end{array}$ & $2(2 \%)$ & $12(15 \%)$ & $1(33 \%)$ & $2(22 \%)$ \\
\hline Unauthorised site & $1(1 \%)$ & $11(14 \%)$ & $1(33 \%)$ & 0 \\
\hline Bricks and mortar - owned & $7(8 \%)$ & $6(7 \%)$ & 0 & 0 \\
\hline Bricks and mortar - rented & $3(4 \%)$ & $2(2 \%)$ & 0 & $1(11 \%)$ \\
\hline Other & $1(1 \%)$ & $11(14 \%)$ & 0 & $1(11 \%)$ \\
\hline \multicolumn{5}{|c|}{ CONSIDER } \\
\hline Socially Rented Site & $5(6 \%)$ & $26(32 \%)$ & 8 & $2(22 \%)$ \\
\hline Self-owned site & $4(5 \%)$ & $13(16 \%)$ & 0 & $1(11 \%)$ \\
\hline $\begin{array}{l}\text { Site owned by another } \\
\text { landlord }\end{array}$ & $20(24 \%)$ & $48(59 \%)$ & 0 & $2(22 \%)$ \\
\hline Unauthorised site & $1(1 \%)$ & $34(42 \%)$ & 0 & $4(44 \%)$ \\
\hline Bricks and mortar - owned & $2(2 \%)$ & $14(17 \%)$ & 0 & $2(22 \%)$ \\
\hline Bricks and mortar -rented & $13(16 \%)$ & $20(25 \%)$ & +3 & $3(33 \%)$ \\
\hline Other & 0 & $5(6 \%)$ & 0 & 0 \\
\hline
\end{tabular}

Source: Southern, James and Buckman, 2015. Base 176 respondents who answered the question. Note: this was a multiresponse question hence percentages do not total 100.

\section{Travelling patterns and experiences}

As well as focusing on respondents' residential accommodation, the survey explored travelling patterns in order to help understand the requirement for transit accommodation. All respondents were asked whether they had travelled in the last year. Of the 182 respondents who answered the question, $63 \%$ stated that they had travelled in the last year, however, the percentages change quite significantly when broken down by type of Gypsy and Traveller. The data showed that just 28 (33\%) 
of the English Gypsy/ Romany respondents within our sample had done so but 77 (87\%) of the New Travellers had travelled in the last year. Unsurprisingly given their occupation, all three Travelling Showpeople had done so, along with $70 \%$ of respondents within the 'other' category. These research findings are particularly troubling in light of the new planning policy for Gypsies and Travellers which states that only mobile Gypsies and Travellers will be accommodated. A significant proportion of all Gypsies and Travellers had not travelled in the last year and the majority of them were Romany Gypsies, who, as has already been established, are most likely to be vulnerable and to be culturally nomadic. The new planning policy does not state a measure for permanent desistance from 'travelling', but given the historic failure to provide sites for Gypsies and Travellers and the assimilationist approach towards accommodation, it is possible that Gypsies and Travellers will be required to move in to bricks and mortar accommodation.

The survey also explored the reasons why people did and did not travel in the last year. The most frequently mentioned reason given for travelling was work, followed by cultural traditions (such as fayres) and to visit friends or family. The most common reason given by those respondents that had not travelled within the last 12 months was because of work commitments and/or their children's education. Reasons relating to age, ill health, disability (or caring for someone experiencing one of those issues) was the second most common reason given but several people also indicated that they could not travel because there was nowhere for them to stop. These findings shed further light on the issues raised by the requirements in the 2015 planning policy for mobility. Those people who had not travelled in the last year had followed sedentarist patterns of fixed work and education that are not generally associated with traditional Gypsies and Travellers and are ironically the things that Gypsies and Travellers are criticised for not engaging with by stigmatising discourses (Sibley, 1981, Richardson, 2006). The assumption that nomadism equates to mobility implies that those people engaged in fixed work and education are no longer nomadic and therefore no longer require site provision. This is despite the fact that their nomadic tradition extends well beyond the workplace and education, being deeply tied to their social structure and organisation (Levinson and Sparkes, 2004, Kabachnik, 2009). The strong familial ties that traditional Gypsy and Traveller cultures are organised around, providing care for the most vulnerable, may be broken down by the removal of those vulnerable people from their homes due to their lack of mobility under the 2015 planning guidance. Further, the preference of most Gypsies and Travellers to live within the law coupled with the lack of provision of transit spaces to stop on may ultimately preclude them from living according to their cultural needs, again due to the lack of mobility that they can legally partake in.

Those respondents that did travel were asked whether they had either been evicted; or had moved on to avoid eviction in the last year as evidence suggests that one of the key issues for Gypsies and Travellers nationally is their eviction from unauthorised sites (Cemlyn et al, 2009). Eviction procedures have been shown through research to result in poor relations between Gypsies and Travellers and Local Authorities and enforcement agencies, as well as with the public. Regular eviction has also been found to correlate with poor health education and welfare of Gypsy and Traveller communities (Commission for Racial Equality, 2006). The results showed that $20 \%$ of respondents who answered the question had done so. Specifically, 14 respondents reported that they had been evicted and 27 had chosen to move on to avoid eviction. When analysed by group in more detail the data showed that $14 \%$ of the English Gypsies/ Romany respondents that had travelled in the last year had been evicted and $11 \%$ had moved on to avoid eviction. This compared with $12 \%$ of New Travellers that had been evicted and $29 \%$ that had moved on. None of the 
Showpeople within our sample had either been evicted or moved on in the last year. New Travellers have previously been found to avoid eviction as much as possible due to the distress it can cause (James, 2007).

The frequency of being evicted and/or moving on from unauthorised sites varied considerably across the sample. Whilst many respondents said that it had happened to them once or twice, three respondents (one English Gypsy/Romany and two New Travellers) reported that they had moved on more than ten times in the last year, this pattern being fairly typical of behaviour to avoid eviction (James, 2011). For those English Gypsy/Romany respondents that had been evicted, the average number of times was four but the average for moving on was just once. Again this contrasts with the New Travellers within the sample where the average number of evictions was just once but the average number of times that had moved on was three times. The movement of Gypsies and Travellers as a response to potential eviction and/or eviction identified here is interesting as it highlights how a lack of appropriate accommodation provision for Gypsies and Travellers can have multiple consequences and can be resource intensive for the public services (police, local authorities, health and welfare providers) who have to deal with the eviction process, as has been previously noted (Morris and Clements, 2002). It also highlights the mobility of Gypsies and Travellers caught up in this cycle of eviction. Hence, may again augment the likelihood of provision for Gypsies and Travellers, particularly New Travellers, under the new planning policy requiring evidence of that mobility. However, were these Gypsies and Travellers to settle on a site provided by the new planning policy remit and stop travelling, then they would be subject to potential eviction for not travelling enough!

\section{Conclusion}

This paper has examined the exclusionary experiences of Gypsies and Travellers in a small part of England in order to examine contemporary provision of accommodation for Gypsies and Travellers and the potential future impact of the 'Planning Policy for Travellers' (2015) on Gypsy and Traveller communities. In doing so the paper has suggested that perceptions of nomadism that rely on mobility in the delivery of planning policy have extensive implications for Gypsy and Traveller communities. This example of a disjuncture between the meaning of nomadism to Gypsies and Travellers and policy makers may go some way to explaining the implementation gap between wider European policies for Roma inclusion and delivery of appropriate accommodation for those communities, as well as wider engagement with them.

The paper has evidenced the failure of policy and legislation in England to provide appropriate accommodation to Gypsies and Travellers who consequently live in poor conditions with limited access to amenities, education, and welfare. The failure to provide appropriate accommodation for Gypsies and Travellers in England has also resulted in increased mobility of some groups, partly in search of places to stop and stay and partly to avoid eviction enforcement. Paradoxically, those groups that are evidenced here as least mobile are those that are recognised by Race Relations legislation as ethnic groups. Within government planning policy, the key governmental tool for accommodation provision, accommodation is determined on the basis of mobility. Hence, traditional Gypsies and Travellers who are recognised as ethnic groups are the least likely to be accommodated in the future and could potentially risk eviction from their current settled homes on sites.

Augmenting the paradoxical nature of the Planning Policy for Travellers (2015) is the research finding 
that those most at risk are also the most vulnerable: those who are very young and very old. Further, provision of accommodation for those currently mobile is likely to be taken away if mobility desists.

State policies that pursue sedentarist binary approaches to nomadism that simply distinguish between mobile communities and sedentary communities fail doubly. Firstly, they fail to provide accommodation that represents the fluidity of mobility in nomadic communities which often requires a sedentary base and places to stop and stay on. Secondly they fail to recognise the importance of cultural nomadism that does not involve mobility but does require appropriate site accommodation. In order to enact inclusionary policies, as lobbied for by civil-society organisations representing Gypsies, Travellers and Roma and set out by European policies and initiatives, state policies need to recognise how nomadism manifests as mobility and culture; only then will Gypsies, Travellers and Roma attain access to their rights in civil society.

(1) Those Gypsies and Travellers living on local authority owned sites as tenants have some security of tenure under the Mobile Homes Act 1983, though this protection does not reach those living on private sites.

\section{References}

Acton, T. (2010), Theorising Mobility: Migration, nomadism, and the social reconstruction of ethnicity. In: Romani Mobilities in Europe Conference. University of Oxford.

Acton, T. (2015), Brentwood Gypsy Support Group; Lessons to be learned from a very small NGO. In: Gypsy Lore Society Annual Meeting 2015. Academy of Sciences of Moldova, Chisinau, Moldova.

Brearley, M. (2001), The Persecution of Gypsies in Europe. American Behavioural Scientist, Vol. 45 No. 4, pp 588-599.

Brown, P., Henning, S. and Niner, P. (2010), Assessing local authorities' progress in meeting the accommodation needs of Gypsy and Traveller communities in England and Wales: 2010 update. London: EHRC.

Brown, P., Dwyer, P. J., Martin, P., Scullion, L. and Turley, H. (2015), Rights, responsibilities and redress?: Research on policy and practice for Roma inclusion in ten member states: Final Report. Research Report. European Commission.

Cemlyn, S., Greenfields, M., Burnett, S., Matthews, Z. and Whitwell, C. (2009), Inequalities experienced by Gypsy and Traveller Communities: A review, London: EHRC.

Clark, C. (2006), Who are the Gypsies and Travellers of Britain. In: Clark C and Greenfields M (eds) Here to Stay: The Gypsies and Travellers of Britain. Hatfield: University of Hertfordshire Press.

Commission for Racial Equality. (2006), Common Ground: Equality, good race relations and sites for Gypsies and Irish Travellers. London: CRE.

Council of Europe. (2011), The Council of Europe: Protecting the rights of Roma. Strasbourg: Council of Europe. 
Department for Communities and Local Government. (2015) Planning policy for traveller sites. DCLG.

Ellis, G. and McWhirter, C. (2008), Land-use and Planning and Traveller-Gypsies: Towards Nonprejudicial Practice. Planning, Practice and Research, Vol. 23 No. 1, pp. 77-79.

Erfani-Ghettani, R. (2012), Localism, populism and the fight against sites. Available at: http://www.irr.org.uk/news/localism-populism-and-the-fight-against-sites/ (accessed: 15 October 2015)

European Union Minorities and Discrimination Survey. (2012), Data in Focus Report: Minorities as Victims of Crime. EU: European Union Agency for Fundamental Rights.

Frazer, H. and Marlier, E. (2011), Promoting the social inclusion of Roma. EU: Employment, Social Affairs and Equal Opportunities.

Friends, Families and Travellers. (2015), Planning Permission For Your Home: Latest changes to planning for Gypsies \& Travellers. Available at: http://www.gypsy-traveller.org/where-you-live2/planning-2/ (accessed: 12 October 2015).

Greenfields, M. and Brindley, M. (2016), Impact of insecure accommodation and the living environment on Gypsies' and Travellers' health. The Traveller Movement.

Greenfields, M. and Smith, D. M. (2009), Housed Gypsy Travellers, Social Segregation and the Reconstruction of Communities. Housing Studies, Vol. 25 No. 3, pp. 397-412.

Halfacree, K. (1996), Out of Place in the Country: Travellers and the 'Rural Idyll'. Antipode, Vol. 28 No. 1 , pp. $42-72$.

Holloway, S. L. (2005), Articulating otherness? White Rural Residents Talk about Gypsy-Travellers. Transactions of the Institute of British Geographers, Vol. 30 No. 3, pp. 351-367.

lovita, R.P. and Schurr, T.G. (2004), Reconstructing the Origins and Migrations of Diasporic Population: The Case of the European Gypsies. American Anthropologist, Vol 106 No. 2, pp. 267-281.

Johnson, C. and Ryder, A. (2015) New government measures on Gypsies and Travellers on a collision course with human rights. Available at: http://www.irr.org.uk/news/new-government-measures-ongypsies-and-travellers-on-a-collision-course-with-human-rights/ (accessed on: 16 October 2015).

James, Z. (2007), Policing Marginal Spaces: Controlling Gypsies and Travellers. Criminology and Criminal Justice: An International Journal, Vol. 7 No.4, pp. 367-389.

James, Z. (2011), Gypsies and Travellers in the Countryside: managing a risky population. In: Yarwood, R. and Mawby, R.I. Constable Countryside? Policing, Governance and Rurality. Ashgate James, Z. (2014), 'Offenders or Victims?: An exploration of Gypsies and Travellers as a policing paradox'. In: Phillips, C. (Ed) New Directions in Race, Ethnicity and Crime. Routledge

James, Z. and Smith, D. (2017), Roma inclusion post Brexit: a challenge to existing rhetoric? Safer Communities: A journal of practice, opinion and research, Vol. 16 No. 4, pp. 186-195 
Kabachnik, P. (2009), To choose, fix or ignore culture? The cultural politics of Gypsy and Traveller mobility in England. Social and Cultural Geography, Vol. 10 No. 4, pp. 461-479

Kabachnik, P. (2010), Place Invaders: Constructing the nomadic threat in England. The Geographical Review, Vol 100 No. 1, pp. 90-108.

Levinson, M. P. and Sparkes, A. C. (2004), Gypsy identity and orientation to space. Journal of Contemporary Ethnography, Vol. 36 No. 6, pp. 704-734.

Merriman, P. (2015), Mobilities 1: Departures. Progress in Human Geography, Vol. 39 No. 1, pp. 8795

Mirga, A. (2009), The Extreme Right and Roma and Sinti in Europe: A New Phase in the Use of Hate Speech and Violence?. Roma Rights Quarterly, Vol. 1 2009, pp. 5-9.

Morris, R. and Clements, L. (2002), At What Cost? The Economics of Gypsy and Traveller Encampments. Bristol: The Policy Press.

Ni Shuinear, S. (1994), Irish Travellers, ethnicity and the origins question. In: McCann, M., O Siochain, S. and Ruane, J. (Eds) Irish Traveller: Culture and Ethnicity. Belfast: Institute of Irish Studies, Queen's University.

Niner, P. (2004), Counting Gypsies and Travellers: A review of the Gypsy caravan count system. London: Office of the Deputy Prime Minister.

ODPM (2006), Gypsy and Traveller Accommodation Assessments: Draft Practice Guidance. ODPM: Gypsy and Traveller Unit.

Okely, J. (1983), The Traveller-Gypsies, Cambridge: Cambridge University Press.

OSCE (2011), Hate Crimes in the OSCE Region: Incidents and Responses. Annual Report for 2010. Warsaw: OSCE ODIHR.

OSCE (2012), Hate Crimes in the OSCE Region: Incidents and Responses. Annual Report for 2011. Warsaw: OSCE ODIHR.

Phillips, C. and Bowling, B. (2008), Racism, ethnicity and criminology: Developing minority perspectives. In: Spalek, B. (ed) Ethnicity and Crime: A Reader. Maidenhead: McGraw Hill.

Richardson, J. (2006), Talking about Gypsies: The Notion of Discourse as Control. Housing Studies, Vol. 21 No. 1, pp. 77-96.

Shubin, S. (2010), "Where can a Gypsy Stop?" Rethinking Mobility in Scotland. Antipode, Vol. 43 No. 2, pp. 494-524.

Shubin, S. (2011), Travelling as being: understanding mobility amongst Scottish Gypsy Travellers. Environment and Planning A, Vol. 43, pp. 1930-1947

Sibley, D. (1981), Outsiders in Urban Societies. Oxford: Blackwell. 
Sibley, D. (1988), Purification of space. Environment and Planning D: Society and Space, Vol. 6 no. 4, pp. 409-421.

Southern R., James, Z. and Buckman, E. (2015), Supporting an Assessment of the Accommodation Needs of Gypsies and Travellers in Cornwall 2015. Southern Horizons with Plymouth University and Buckman Associates Report.

Stewart, M. (2012), Populism, Roma and the European Politics of Cultural Difference. In: Stewart, M. (ed) The 'Gypsy' Menace: Populism and the New Anti-Gypsy Politics. London: Hurst.

Sturgis, P. (2008), Designing Samples. In: Gilbert, N. (ed) Researching Social Life. London: Sage.

The Traveller Movement (2015), Government changes to Planning Policy for Traveller sites. Briefing Paper: The Traveller Movement.

Thomas, H. (2000), Race and Planning: The UK Experience. London: UCL Press.

Walker Hudson, L. (2009), Hearing the human rights voices of Gypsy and traveller mothers in the UK. Journal of Social Welfare and Family Law, Vol. 31 No. 2, pp. 121-132

Wilkin, A., Derrington, C., White, R., Martin, K., Foster, B., Kinder, K. and Rutt, S. (2010), Improving the outcomes for Gypsy, Roma and Traveller pupils: final report. Research Report DFE-RR043. Department for Education. 